\title{
Optimization Of Adaptive Control Technique For Grid Integrated Pv-Dstatcom
}

\author{
Vasa Satyanarayana a, Dr. Prabodh Kumar Khampariyab \\ ${ }^{a}$ Research Scholar, Dept. of Electrical Engineering, \\ Sri Satya Sai University of Technology \& Medical Sciences, Sehore, Bhopal Indore Road, Madhya Pradesh, India \\ ${ }^{\mathbf{b}}$ Research Guide, Dept. of Electrical Engineerin, \\ Sri Satya Sai University of Technology \& Medical Sciences, Sehore, Bhopal Indore Road, Madhya Pradesh, India
}

Article History: Received: 11 January 2021; Accepted: 27 February 2021; Published online: 5 April 2021

\begin{abstract}
This paper depicts an optimization of adaptive control strategy for grid integrated PV-DSTATCOM and dynamic power channel inverter topographies and their control plans using mechanical rules and advanced high-power courses of action. In this paper we will accomplish DSATCOM based maximum power point tracking (MPPT) method for a three stage framework to improve power quality and backing the three stage AC grid by providing power both to the grid and the associated loads. The proposed framework functions as DSTATCOM improving power quality and the power is moved from the grid to the heap. The exhibition of DSTATCOM and the power point is noticed and it is by all accounts all around performed to restrict the music. The test framework is actualized utilizing MATLAB SIMULINK programming. The framework is named as a brilliant as it can perform the two modes consequently detecting the PV power and is fit for multidirectional power stream.Additionally we will reproduce and print results for optimization of adaptive control technique for grid integrated solar cells. The trial approval is completed on a created model in the research facility under fluctuating modes. The proposed PV grid tied framework is fit for working nonstop. During daylight conditions, the proposed framework performs double elements of improving power quality by functioning as DSTATCOM and furthermore moves power to the heap and the grid got from PV cluster. Notwithstanding, during night or shady conditions.
\end{abstract}

Keywords: Grid, PV, adaptive, shunt, power, current, voltage, control, integrated.

\section{Introduction}

A MPPT is essentially a productive DC to DC converter used to expand the power yield of a solar panel. The primary MPPT was developed by a little Australian organization got back to AERL path in 1985, and this innovation is presently utilized in basically all grid-interface solar inverters and numerous solar charge controllers. The working standard of a MPPT solar charge controller is somewhat basic - because of the fluctuating level of daylight (irradiance) arriving on a solar panel for the duration of the day, the panel voltage and current persistently changes. To create the most power, the maximum power point tracker moves through the panel voltage to locate the 'sweet spot' or the best blend of voltage and current to deliver the maximum power. The MPPT is intended to consistently follow and change the voltage to produce the most power regardless of what season of day or climate conditions (Note, just top of the line MPPT controllers will identify fractional concealing, or have the option to follow various power points).

Utilizing this shrewd innovation, the solar panel effectiveness increments and the measure of energy produced is up to $30 \%$ in excess of a PWM solar charge controller. For a MPPT controller to work effectively, the voltage of the solar panel (or solar cluster) should be at any rate $4 \mathrm{~V}$ to $5 \mathrm{~V}$ higher than the battery 'charging' voltage (not the ostensible battery voltage). This is on the grounds that the panel voltage will drop under shady condition or when the solar panel temperature increments. All together for the MPPT to work effectively the panel voltage should be consistently higher than the battery voltage under all conditions. On account of $12 \mathrm{~V}$ batteries the panel voltage drop is certifiably not a major issue as generally $(12 \mathrm{~V})$ solar panels work in the $18 \mathrm{~V}$ to $22 \mathrm{~V}$ territory, which is a lot higher than the normal $12 \mathrm{~V}$ battery charge voltage of $14.4 \mathrm{~V}$.Also, $(24 \mathrm{~V})$ solar panels are not an issue as they work in the $30 \mathrm{~V}$ to $40 \mathrm{~V}$ territory.

On account of $24 \mathrm{~V}$ batteries there is no issue when at least 2 solar panels are associated in arrangement, yet there is an issue when just 1 solar panel is associated. Generally normal (24V) 60 cell solar panels have a Vmp of $30 \mathrm{~V}$ to $34 \mathrm{~V}$. While this is higher than the battery charging voltage of around $28 \mathrm{~V}$, the issue is the point at which the panel temperature increments on an exceptionally hot day, the panel voltage can drop by up to $6 \mathrm{~V}$, and end up well beneath the $28 \mathrm{~V}$ battery charge voltage keeping it from completely charging. While charging $48 \mathrm{~V}$ batteries, the framework will require at any rate 2 panels in arrangement however will perform much better with at least 3 panels in arrangement, contingent upon the maximum voltage of the charge controller. Since most $48 \mathrm{~V}$ solar charge controllers have a maximum voltage ( $\mathrm{Voc}$ ) of $150 \mathrm{~V}$ this considers 3 panels to be associated in arrangement. The higher voltage $250 \mathrm{~V}+$ charge controllers can have strings of at least 5 panels which is significantly more effective on bigger solar clusters as it decreases the quantity of strings in equal and thus brings down the current. Grid associated PV frameworks consistently have an association with the public power grid through a reasonable inverter in light of the fact that a photovoltaic panel or exhibit (different PV panels) just convey DC power. 


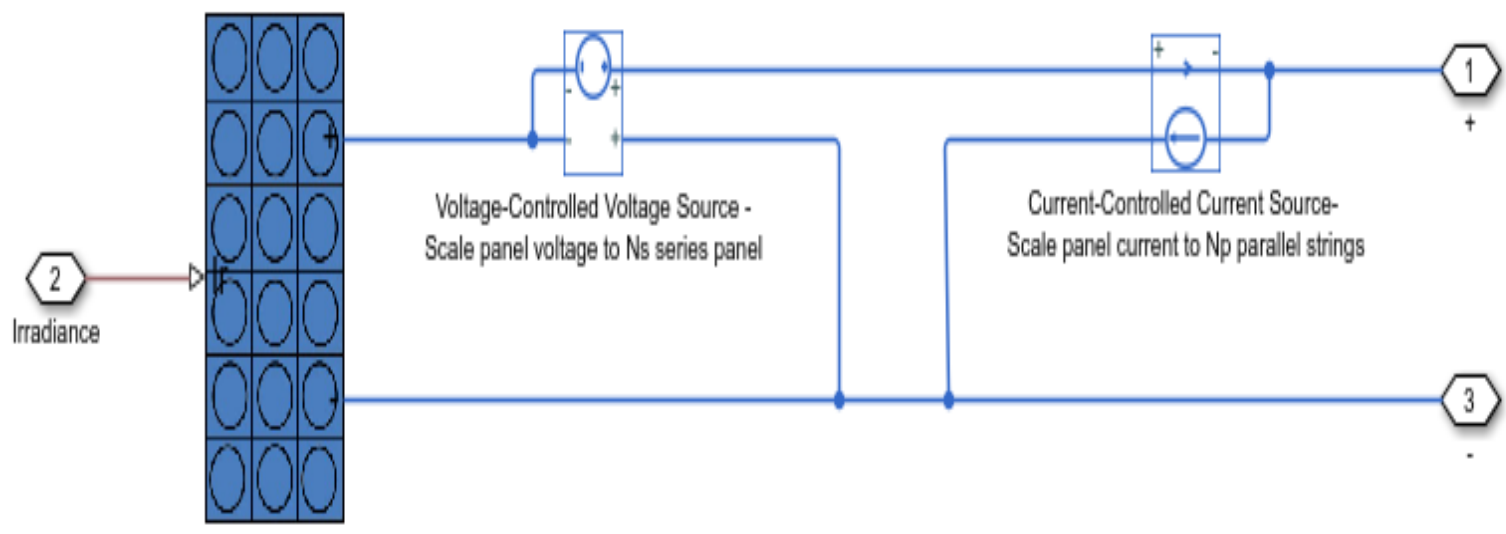

Solar Panel

Figure 1 Solar Panel Connection

Just as the solar panels, the extra segments that make up a grid associated PV framework contrasted with an independent PV framework are: Inverter: The inverter is the main piece of any grid associated framework. A grid-tied framework is an essential solar establishment that utilizes a standard grid-tied inverter and doesn't have any battery stockpiling. This is ideal for clients who are now on the grid and need to add solar to their home. These frameworks can meet all requirements for state and government motivations which help to pay for the framework. Grid-tied frameworks are easy to plan and are extremely savvy since they have generally couple of segments. The fundamental target of a grid-tied framework is to bring down your energy bill and advantage from solar motivators. One weakness of this sort of framework is that when the power goes out, so does your framework. This is for wellbeing reasons since linemen chipping away at the power lines need to know there is no source taking care of the grid. Grid-tied inverters need to consequently detach when they don't detect the grid. This implies that you can't give power during a blackout or a crisis and you can't store energy for some time in the future. You likewise can't control when you utilize the power from your framework, for example, during top interest time. Yet, in the event that a client has an essential grid-tied framework, they are not stuck between a rock and a hard place on the off chance that they need to add stockpiling later.

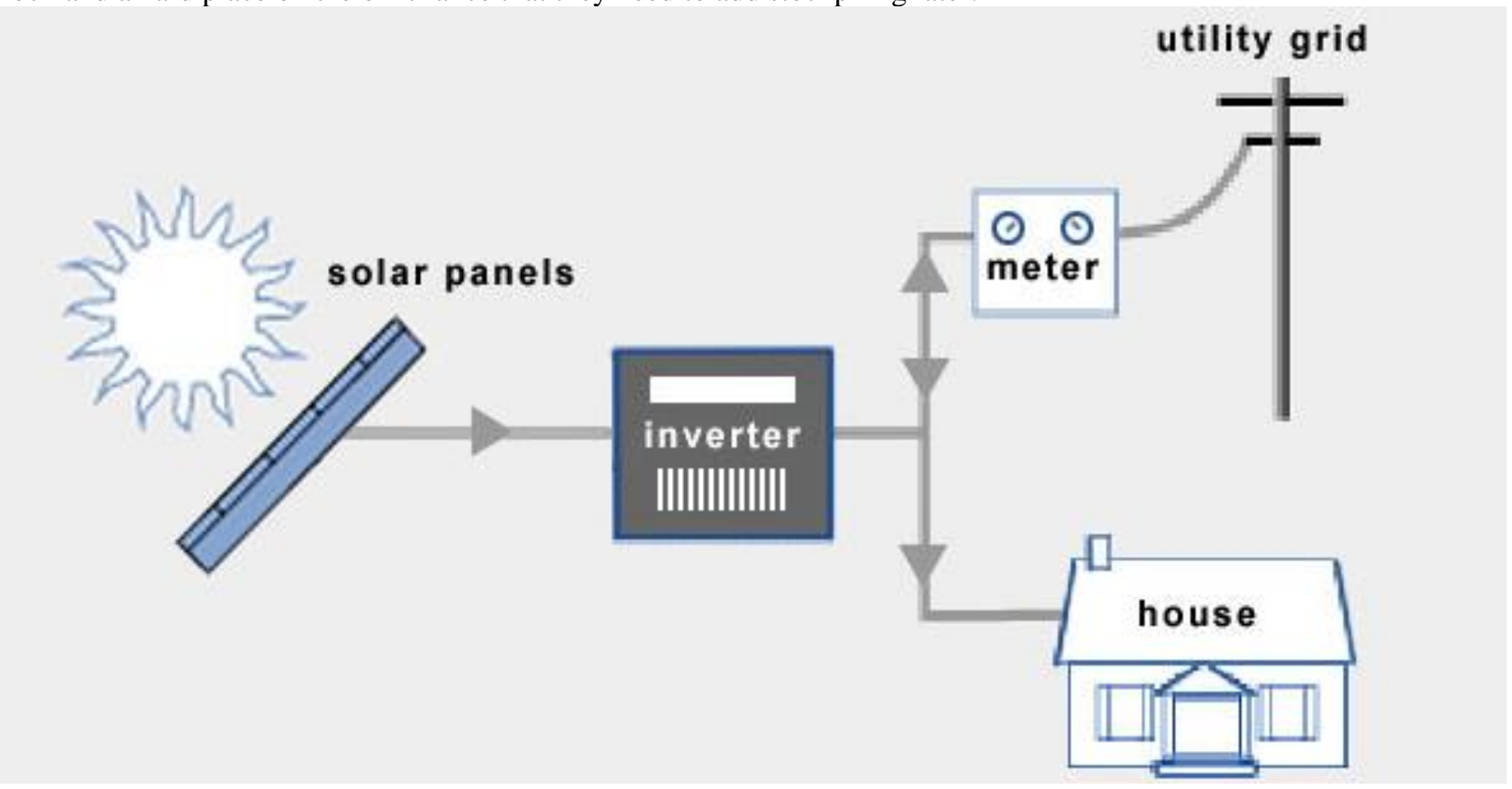

Figure 2 Grid Connection

The arrangement is doing an AC-coupled framework where the first grid tied inverter is combined with a battery back-up inverter. This is an incredible answer for clients who need to introduce solar presently to exploit motivators, yet aren't prepared to put resources into the batteries right now. A client can profit by net-metering on the grounds that when the solar is creating more than they are utilizing, they can send power back to the grid. However, in occasions when the heaps are higher than what the solar is creating they can purchase power from 
the utility.The client isn't dependent on the solar to power the entirety of their heap. The principle remove is that when the grid goes down, the solar is down too and there's no battery back-up in the framework. The inverter separates as much DC (direct current) power as conceivable from the PV cluster and converts it into clean mains $\mathrm{AC}$ (rotating current) power at the correct voltage and recurrence for taking care of into the grid or for providing homegrown burdens. It is essential to pick the most ideal quality inverter for the financial plan permitted as the principle contemplations in grid associated inverter decision are: Power Maximum high and low voltage power the inverter can deal with and Efficiency How productively does the inverter convert solar power to AC power. Power Meter: The power meter additionally called a Kilowatt hour $(\mathrm{kWh})$ meter is utilized to record the progression of power to and from the grid. Twin $\mathrm{kWh}$ meters can be utilized, one to show the electrical energy being burned-through and the other to record the solar power being shipped off the grid. A solitary bidirectional $\mathrm{kWh}$ meter can likewise be utilized to show the net measure of power taken from the grid. A grid associated PV framework will back off or stop the aluminum circle in the electric meter and may make it turn in reverse.

This is for the most part alluded to as net metering. AC Breaker Panel and Fuses: The breaker panel or wire box is the typical kind of wire box furnished with a homegrown power supply and establishment except for extra breakers for inverter or potentially channel associations. Wellbeing Switches and Cabling. A photovoltaic exhibit will consistently create a voltage yield in daylight so it should be conceivable to separate it from the inverter for support or testing. Isolator switches appraised for the maximum DC voltage and current of the cluster and inverter wellbeing switches should be given independently simple admittance to disengage the framework. Other wellbeing highlights requested by the electrical organization may incorporate earthing and breakers.

The electrical links used to associate the different segments should likewise be effectively appraised and estimated. The Electricity Grid: Finally the power grid itself to associate as well, on the grounds that without the utility grid it's anything but a Grid Connected PV System. A grid associated framework without batteries are the easiest and least expensive solar power arrangement accessible, and by not charging and keep up batteries they are likewise more productive. Note that a grid associated solar power framework is certainly not an autonomous power source not at all like an independent framework. Should the mains supply from the electrical grid be intruded on, the lights may go out, regardless of whether the sun is sparkling. One approach to conquer this is to have some type of momentary energy stockpiling incorporated into the plan.

\section{LITERATURE REVIEW}

S. Mani Kuchibhatla (2020): In power quality (PQ) issues, the adaptable AC transmission framework (FACTS) gadgets have been built up the genuine power and lessening the PQ issues of the power framework. Here the PQ investigation in photovoltaic (PV), wind turbine (WT) framework with grid integrated static exchanged channel compensator (SSFC) is controlled by adaptive procedure. The adaptive procedure works with the joined cycle of $\mathrm{CFA}$ and recurrent neural organization (RNN) calculation. The proposed adaptive method is controlling the unpredictable exchanging cycle of the shunt capacitor banks of a tuned arm channel in SSFC gadget. The curiosity of the proposed method is improved for energy proficiency and request the executives in grid use measure. Here a power infusion model of SSFC is considered to control the genuine power stream control regarding grid use. The exchanging cycle is controlled by offsetting control signal created with the assistance of heartbeat width balance (PWM) measure. To tweak the PWM is utilized by two controllers, which depends on a tri-circle genuine blunder oversaw joined weighted changed relative necessary subordinate controller. The proposed SSFC framework is planned and executed in MATLAB/Simulink stages and the exhibition is approved for certain current gadgets, for example, bound together power stream controller and SSFC gadgets.

Aadesh Kumar Arya (2019): In request to examine the conveyance framework (DS) to limit the power misfortunes and improve power quality, finding precise position size of dissemination static compensator (DSTATCOM) is basic. In this paper, a metaheuristic optimization strategy, the gravitational inquiry calculation (GSA) is proposed for the investigation of DS with precise putting and measuring of circulated static coordinated compensator (D-STATCOM) for power misfortune decrease, least voltage profile record, improvement in voltage profile and yearly energy putting something aside for conveyance network administrator. The adequacy of the proposed calculation is tried on IEEE 33 and IEEE 69 transport frameworks, and execution of GSA has been contrasted and different procedures, for example, invulnerable calculation, bat calculation and affectability approach strategy for ideal allotment of D-STATCOM. It is discovered that the best execution is accomplished by the proposed strategy. Forward-in reverse range strategy is utilized for the heap stream arrangements in this paper.

Atma Ram Gupta (2019): The point of this paper is to break down unequal outspread circulation frameworks (UBRDS) with the dissemination static compensator (D-STATCOM). The principle targets of this paper are DSTATCOM designation in UBRDS with a goal of giving receptive power backing to upgrade voltage profile and decrease line misfortunes of the conveyance organization, assurance of ideal D-STATCOM rating exposed to minimization of total expense, and effect of D-STATCOM arrangement on improving power factor and reserve funds in expense of energy misfortune. The investigation is led on an enormous mechanical burden model with light, medium and high stacking situations. Further, the effect of burden development is additionally considered 
for better arranging of the power dissemination framework. The outcomes are gotten on standard 25-transport UBRDS to check the achievability of the proposed procedure.

\section{PROPOSED METHODOLOGY}

Maximum power point tracking (MPPT) is a calculation executed in photovoltaic (PV) inverters to ceaselessly change the impedance seen by the solar cluster to keep the PV framework working at, or near, the pinnacle power point of the PV panel under differing conditions, such as changing solar irradiance, temperature, and burden. Solar inverters execute MPPT calculations to augment the power created by PV frameworks. The calculations control the voltage to guarantee that the framework works at "maximum power point" (or pinnacle voltage) on the power voltage bend, as demonstrated as follows. MPPT calculations are commonly utilized in the controller plans for PV frameworks. The calculations represent factors, for example, factor irradiance (daylight) and temperature to guarantee that the PV framework creates maximum power consistently. A grid-tied framework is a fundamental solar establishment that utilizes a standard grid-tied inverter and doesn't have any battery stockpiling. This is ideal for clients who are now on the grid and need to add solar to their home. These frameworks can fit the bill for state and government motivating forces which help to pay for the framework. Grid-tied frameworks are easy to plan and are exceptionally financially savvy since they have moderately couple of parts. The fundamental target of a grid-tied framework is to bring down your energy bill and advantage from solar motivating forces. One inconvenience of this sort of framework is that when the power goes out, so does your framework. This is for security reasons since linemen chipping away at the power lines need to know there is no source taking care of the grid.

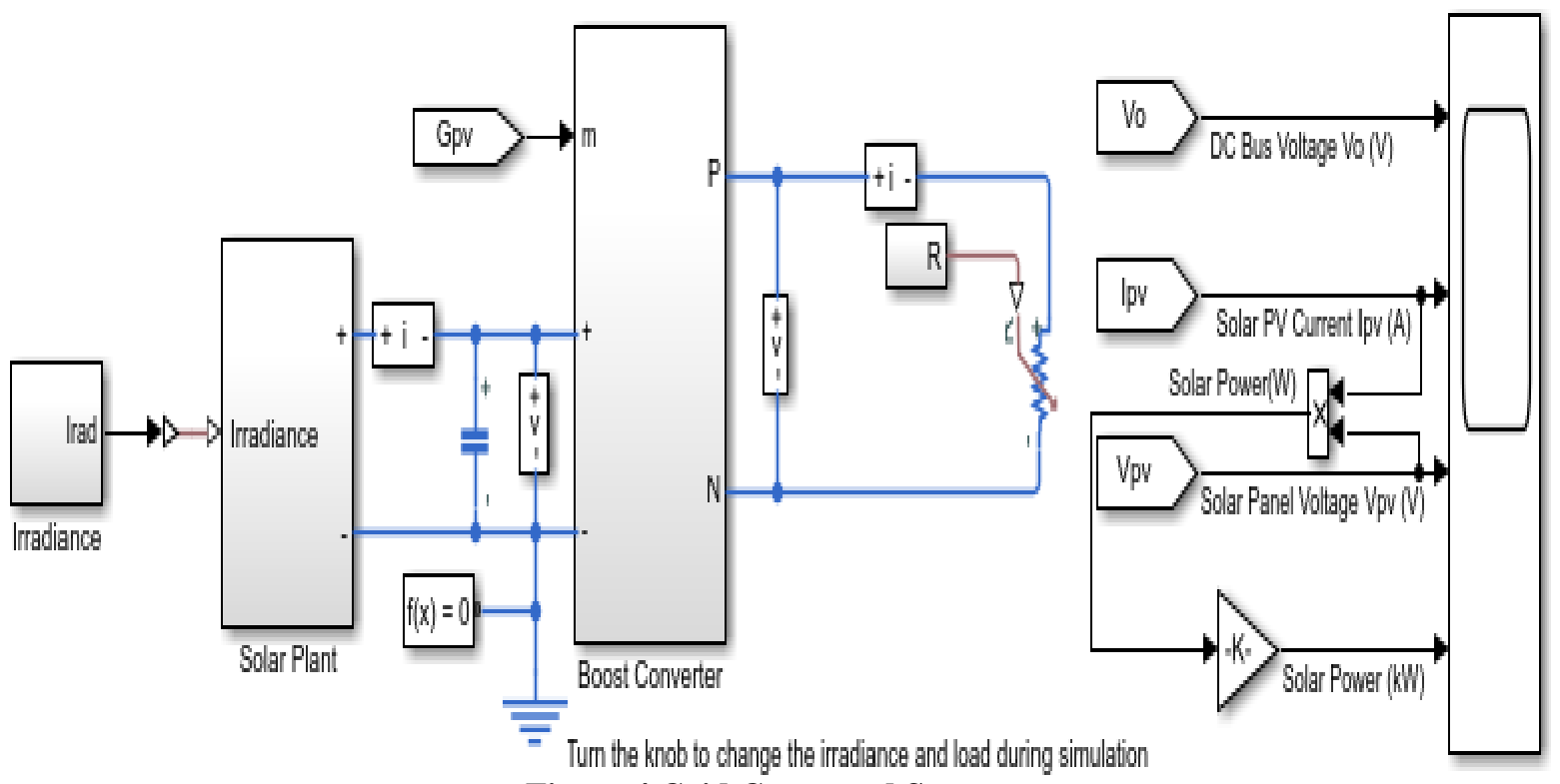

Figure 4 Grid Connected System

Grid-tied inverters need to naturally detach when they don't detect the grid. This implies that you can't give power during a blackout or a crisis and you can't store energy for some time in the future. Additionally can't control when you utilize the power from your framework, for example, during top interest time. However, in the event that a client has an essential grid-tied framework, they are not in a tight spot in the event that they need to add stockpiling later. The arrangement is doing an AC-coupled framework where the first grid tied inverter is combined with a battery back-up inverter. This is an incredible answer for clients who need to introduce solar presently to exploit motivating forces, however aren't prepared to put resources into the batteries right now. A client can profit by net-metering on the grounds that when the solar is creating more than they are utilizing, they can send power back to the grid. However, in occasions when the heaps are higher than what the solar is delivering they can purchase power from the utility. The client isn't dependent on the solar to power the entirety of their heap. The principle remove is that when the grid goes down, the solar is down too and there's no battery back-up in the framework. The solar plant subsystem models a solar plant that contains equal associated strings of solar panels. The solar panel is demonstrated utilizing the Solar Cell block from the Sims cape Electrical library. Given the predetermined DC transport voltage, solar cell qualities and determined power rating, a computation is made of the solar panel string length and number of equal associated strings. Interfacing different panels can slow the reproduction since it expands the quantity of components in a model. By expecting uniform irradiance and temperature across all the solar panels, it is conceivable to decrease the quantity of solar components by utilizing the controlled current and voltage sources as appeared in the solar panel subsystem. 


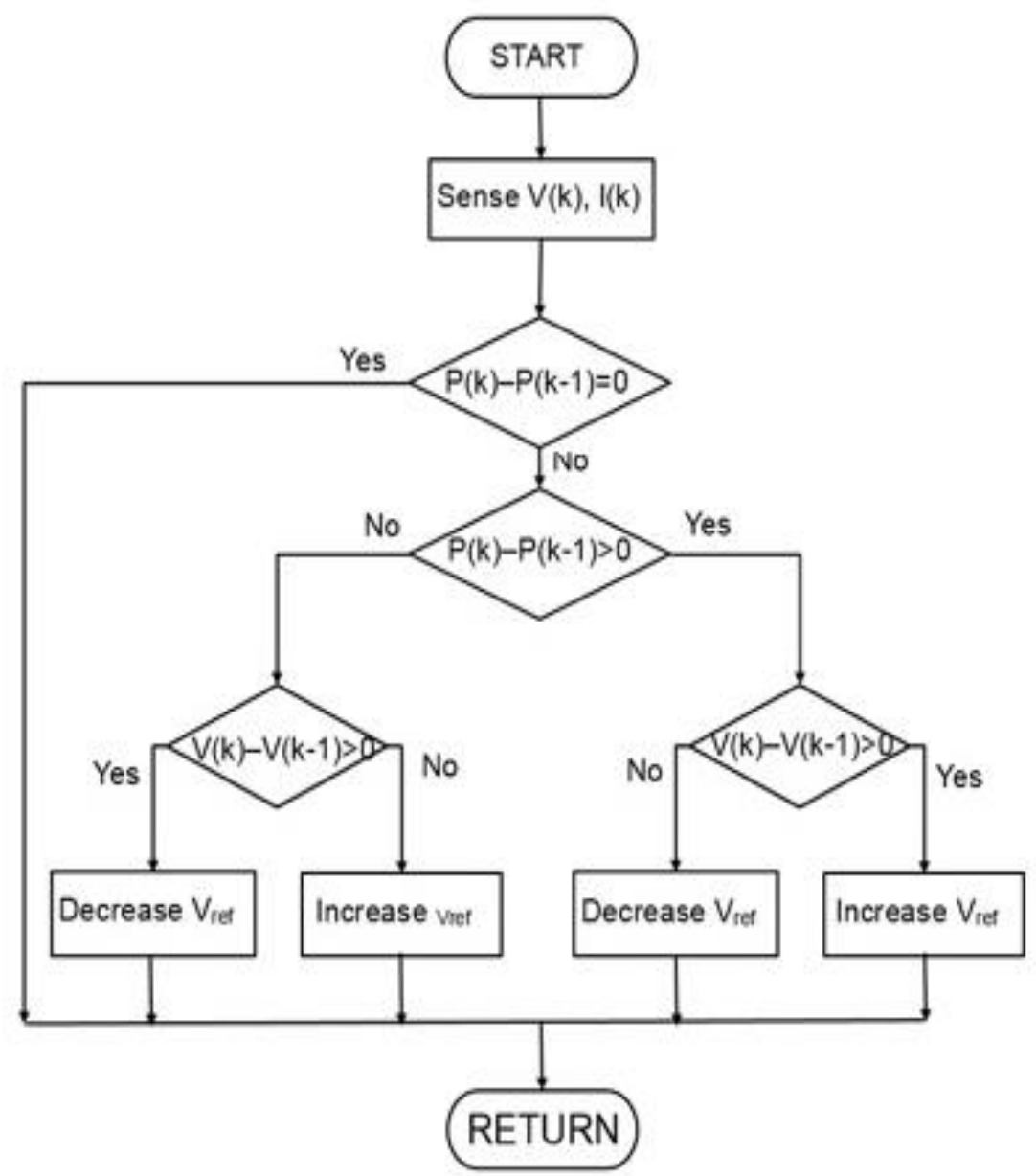

Figure 3 MPPT Algorithm

WO MPPT methods are actualized utilizing the variation subsystem. Set the variation variable MPPT to 0 to pick the bother and perception MPPT technique. Set the variable MPPT to 1 to pick the steady conductance technique. A lift DC-DC converter is utilized to control the solar PV power. The lift converter works in both MPPT mode and voltage control mode. The voltage control mode is utilized just when burden power is not exactly the maximum power produced by solar PV plant given the occurrence irradiance and panel temperature.

\section{EXPERIMENT RESULT}

The under two figure speaks to the outcome got for adaptive control strategy for grid integrated PVDSTATCOM. The power to voltage bend speaks to the maximum accomplished power for the individual voltage goes from 0 to $50 \mathrm{v}$. We have accomplished maximum power point of 140w at 50 voltage. In like manner we have separate remedy for current to voltage proportion. The current to voltage proportion speak to the connection among voltage and current for maximum power point tracking. The under two recreation diagram portrays power optimization utilizing adaptive technique called maximum power point tracking. This control strategy streamlined power for grid integrated PV-DSTATCOM which shows our technique is demonstrated. MPPT innovation encouraged here to pick up maximum achievable from the solar panel regarding certain constraints, for example, heat, ill-advised wiring, and inappropriate point and so on 


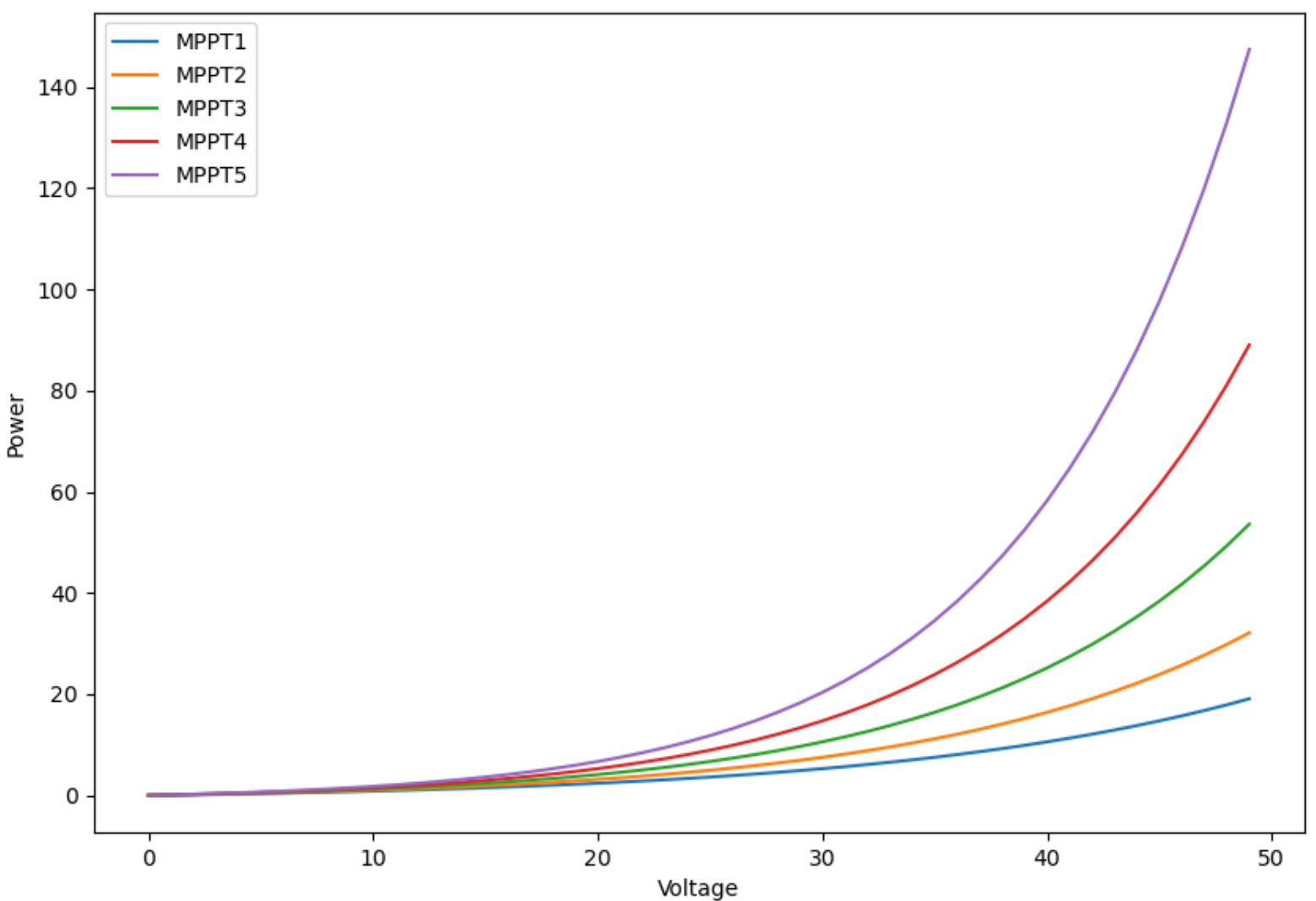

Figure 5 Power to Voltage Curve

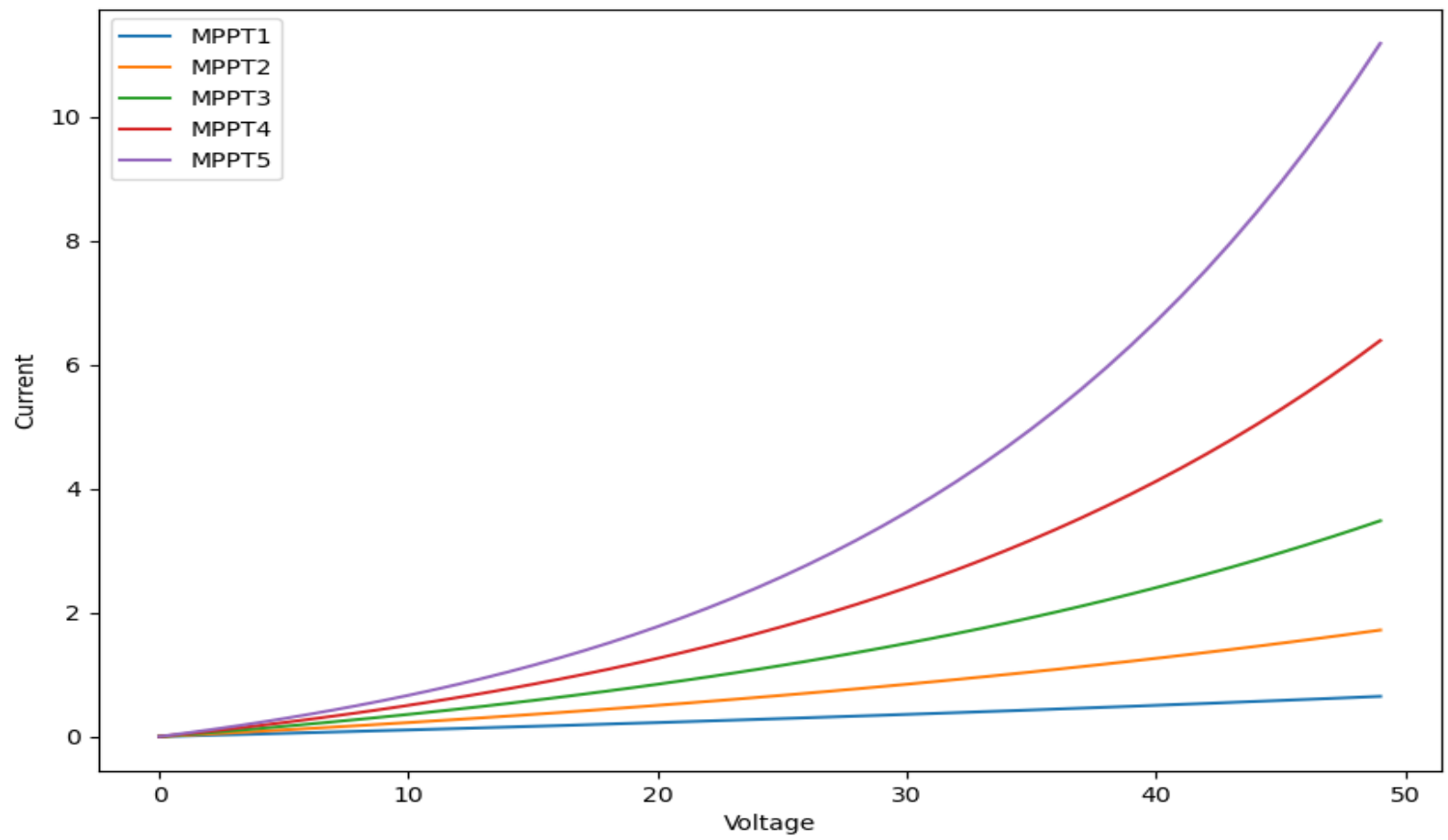

Figure 6 Current to Voltage Curve

\section{CONCLUSION}

In this paper we have actualized headway of adaptive control technique for grid integrated PV-DSTATCOM. A maximum power point tracking has been utilized for control DSTATCOM and its exhibition has been noticed palatable with non-sinusoidal and twisted voltage of AC mains under burden variety. A DSTATCOM has been executed for a three-stage grid integrated PV framework for getting maximum power by tracking the voltage to 
current apportion dependent on the radiant produced by the solar framework. The exhibition of DSTATCOM with its maximum power point tracking has been shown for sounds disposal, receptive power remuneration and burden adjusting. Our adaptive control instrument will assist with accomplishing maximum power by noticing all accessible power from the solar grid framework. The DC connect voltage of the DSTATCOM has likewise been controlled to wanted an incentive under time differing load conditions. The grid associated PV framework will assist us with accomplishing similar power during stormy and overcast days. Herewith we have presumed that we have actualized optimization of adaptive control technique for grid integrated PV-DSTATCOM and demonstrated the power optimization utilizing the reproduction device.

\section{REFERENCES}

1. Kuchibhatla, S.M., Padmavathi, D. \& Rao, R.S. Adaptive technique for PQ analysis in renewable sources with grid integrated SSFC. J Ambient Intell Human Comput 11, 2421-2434 (2020). https://doi.org/10.1007/s12652-019-01283-5

2. Arya, A.K., Kumar, A. \&Chanana, S. Analysis of Distribution System with D-STATCOM by Gravitational Search Algorithm (GSA). J. Inst. Eng. India Ser. B 100, 207-215 (2019). https://doi.org/10.1007/s40031-019-00383-2

3. Gupta, A.R., Kumar, A. Reactive power deployment and cost benefit analysis in DNO operated distribution electricity markets with D-STATCOM. Front. Energy 13, 86-98 (2019). https://doi.org/10.1007/s11708-017-0456-8

4. Chawda, G.S.; Shaik, A.G. Smooth Grid Synchronization in Weak AC Grid with High Wind Energy Penetration using Distribution Static Compensator. In Proceedings of the 2019 2nd International Conference on Smart Grid and Renewable Energy (SGRE), Doha, Qatar, 19-21 November 2019; IEEE: Piscataway, NJ, USA, 2019; pp. 1-6.

5. Chawda, G.S.; Shaik, A.G. Adaptive Reactive Power Control of DSTATCOM in Weak AC Grid with High Wind Energy Penetration. In Proceedings of the 2019 IEEE 16th India Council International Conference (INDICON), Rajkot, India, 13-15 December 2019; IEEE: Piscataway, NJ, USA, 2019; pp. 1-4.

6. Chawda, G.S.; Shaik, A.G.; Mahela, O.P.; Padmanaban, S.; Holm-Nielsen, J.B. Comprehensive Review of Distributed FACTS Control Algorithms for Power Quality Enhancement in Utility Grid With Renewable Energy Penetration. IEEE Access 2020, 8, 107614-107634

7. IRENA. Global Energy Transformation: A Roadmap to 2050; International Renewable Energy Agency: Abu Dhabi, UAE, 2019. 10. Mahela, O.P.; Shaik, A.G. Comprehensive overview of grid interfaced solar photovoltaic systems. Renew. Sustain. Energy Rev. 2017, 68, 316-332.

8. Li, H.; Yang, D.; Su, W.; Lü, J.; Yu, X. An overall distribution particle swarm optimization MPPT algorithm for photovoltaic system under partial shading. IEEE Trans. Ind. Electron. 2018, 66, 265275. 